\title{
Psychiatry and the law: do the fields agree in their views on coercive treatment? Julio Arboleda-Florez
}

\author{
Address: Department of Psychiatry, Queen's University, Kingston Ontario K7L 3N6, Canada \\ from WPA Thematic Conference. Coercive Treatment in Psychiatry: A Comprehensive Review \\ Dresden, Germany. 6-8 June 2007 \\ Published: 19 December 2007 \\ BMC Psychiatry 2007, 7(SuppI I):SI0 doi:10.I I86/I47I-244X-7-SI-SI0
}

This abstract is available from: http://www.biomedcentral.com/I47I-244X/7/SI/SI0

(c) 2007 Arboleda-Florez; licensee BioMed Central Ltd.

Coercion is an element of some treatments in psychiatry and it is contemplated in legislation, which often dictates parameters for involuntary admissions and use of restrictive treatments. A trend in the past years has been to widen the parameters required for commitment, thus extending coercive elements of psychiatric treatments to less immediate situations and into the community as in assertive community treatment strategies and, most pointedly, as in community treatment orders. Elements of coercion could be applied in different ways that range from voluntary acceptance to seemingly adherence to outright refusal and force. How these elements compaginate with legal mandates and how are they justified in psychiatry and in law in a balance between needs for protection and individuality and autonomy will be concepts and strategies to be developed in this lecture. The ethics of coercion will be reviewed from a point of view of human and civil rights, both negative and positive rights of mental patients. In this respect, attention will be placed to the experience of coercion by patients, who is coerced and reasons for the use of this expedient strategy in psychiatry and law. 